\title{
Modelling Effects of Drug Testing Procedures on Performance Trends in the Shot Put
}

\author{
Leon I Foster ${ }^{\text {* }}$, Steve J Haake ${ }^{1}$, Dave M James ${ }^{1}$ and Alan M Nevill ${ }^{2}$
}

${ }^{1}$ The Centre for Sports Engineering Research, Faculty of Health and Wellbeing, Sheffield Hallam University, UK

${ }^{2}$ Faculty of Education, Health and Wellbeing, University of Wolverhampton, UK

\begin{abstract}
Objectives: The effect of performance enhancing drugs on historic performance records in sport is open to interpretation and needs empirical support. Here we addressed this contentious issue by assessing whether a double sigmoidal model could detect decrements in sporting performance attributed to introduction of drug testing protocols.

Methods: Distances thrown by the top 25 male and female shot putters since the end of the $19^{\text {th }}$ century were modelled using a double sigmoid.

Results: First-phase peak acceleration in the men's and women's shot put was reached in 1981 and 1986 respectively coinciding with advent of systematic doping programs. Shot put performance of men and women underwent a second-phase decline of $5.3 \mathrm{~m}$ and $8.9 \mathrm{~m}$, in 1991 and 1994, respectively. Performance decrements in women's shot put were nearly double that for men, but much of this difference resulted from the reduced mass of their shot. Controlling for changes in mass, women's shot put performance appears to decline to a greater extent than men's, based on raw energy calculations.

Conclusions: The double sigmoidal model detected a second-phase decline in shot put performances. We attribute this data feature to onset of improved drug testing protocols and a consequential reduction of doping. The assumption is that drug testing programs of shot putters has been successful and reduced the prevalence of drug taking in that sport. The application of a double sigmoidal model to historic performance statistics can be used to detect unknown interventions in analyses of sports performance.
\end{abstract}

Keywords: Double logistic curves; Nonlinear regression; Drug testing interventions; Performance modelling; Shot put performance; Doping

\section{Introduction}

It has been well documented that athletic performance has increased since the start of the modern Olympic Games in 1896, and many factors have been attributed to this improvement, including changes in population $[1,2]$, globalization [3], technological interventions [4,5] and use of performance enhancing drugs [6]. Performance trends in various sports have been modelled through the implementing various growth functions with the aim of quantifying these influential factors $[5,7,8]$, and predicting limits of human ability $[9,10]$.

One notable, but thus far challenging, intervention to gauge is the influence of performance enhancing drugs, mainly because of uncertainty due to their secretive use in elite-level sport programs. Evidence suggests that from the 1950s to 1980s systematic doping programs were implemented by Eastern bloc countries, as well as the USA, in various "power" events [11,12]. Athletes were, putatively, surreptitiously prescribed different drugs (often without their knowledge), such as anabolic steroids and hormones, to increase muscle mass and, ultimately, their performance [11,12]. Results of these programs can be observed in specific events, where performance curves display an unanticipated trend and peak in the 1980s, before dropping to the present day. Here we implement a model to interpret whether this observed performance decrement might be attributed to the introduction of more effective drugs testing programs during that decade.

One method of investigating effects of drugs testing programs, proposed by Haake and Foster [7,8] to gauge the influence of performance enhancing drugs, was through the modelling of step interventions in 1989 and 2000 using [0,1] indicator variables. These step changes accounted for instantaneous reductions in running performance, presumed to be related to the introduction of improved drug testing protocols. The disadvantages of this method are: (1) the introduction of drug testing procedures might not follow an instantaneous discrete step change profile; and (2), choosing specific dates in which to apply a step change is a subjective process, and date selection might influence reported effects.

An alternative approach is adapted from the methods proposed by Balmer et al. [5] who originally used a double sigmoidal model to identify specific technological interventions in jumping events (e.g. to separate the effect of the Fosbury flop from the evolutionary growth in high-jump performances). In this study, we sought to ascertain whether the model could be used to overcome disadvantages of our original method. We sought to separate the development of drug testing procedures and consequential performance declines, from evolutionary growth in shot put performance. Specifically, we focused on understanding whether the double sigmoidal method could be used to model the effects on shot put performance statistics of improved drug testing procedures.

Recent research $[7,8,13]$ has made use of established online databases [14] that contain all performance statistics since modern competitive records began. Application of a double sigmoidal model

\footnotetext{
*Corresponding author: Leon Foster, Research Associate, Centre for Sports Engineering Research, Sheffield Hallam University, A129 Collegiate Hall, Collegiate Crescent, Sheffield, S. Yorks S10 2BP, UK, Tel: +44 (0)114 225 3996; Fax: +44 (0)114 225 4356; E-mail: I.i.foster@shu.ac.uk

Received July 10, 2014; Accepted November 14, 2014; Published November 18,2014

Citation: Foster LI, Haake SJ, James DM, Nevill AM (2014) Modelling Effects of Drug Testing Procedures on Performance Trends in the Shot Put. J Sports Med Doping Stud 4: 151. doi:10.4172/2161-0673.1000151

Copyright: $\odot 2014$ Foster LI, et al. This is an open-access article distributed under the terms of the Creative Commons Attribution License, which permits unrestricted use, distribution, and reproduction in any medium, provided the original author and source are credited.
} 
to this type of data would facilitate modelling of an underlying evolutionary improvement curve (phase one growth), in addition to curves predicated an external intervention events (phase two growth).

To achieve our aims we chose the shot put event for men and women as a task vehicle for analysis. Performance in such athletic field events is predominantly related to the power an athlete can produce. The shot put event has a competitive aim of "putting" a shot the greatest distance over a number of rounds. Unlike other field events, like the high jump, a single dominant shot putting technique has not emerged, with athletes favoring either the "Glide" or the "Spin" actions. This feature suggests that putting technique is not a dominant factor and that historic technical changes are assumed not to have significantly influenced trends in overall shot put performance. This suggestion makes it an ideal event to examine the evolutionary development of athletic performance over the past century, since few outside interventions, other than possibly drug taking and drug testing, are likely to have influenced performance over time. The shot put is also an old event in which performance data are found in the earliest records of international competitions, signifying that entire historic trends in shot put performance can be examined.

In this study our aim was to utilise the double sigmoidal model originally proposed by Balmer et al. [5] to model the top 25 best performances in each year in male and female shot put competitions recorded over the past century. Model fitting would enable us to quantify the evolutionary development in shot put performances in the past century, in addition to the influence of drug testing procedures, and consequential performance declines, in more recent years. This information will assist in providing potential estimates of current doping levels in elite shot put and whether implemented drug testing procedures have been successful.

\section{Methods}

With institutional ethics approval, data on the top 25 performances were collected from open-source, performance statistics websites $[14,15]$ for the men's and women's shot put event between 1891 and 2012 (women's data from 1921 onwards). Performances were collated such that each athlete appeared only once in the annual list. Figure 1a shows the top 25 performances for the men's shot put event from the 1890s onwards and Figure 1b shows the same data for the women's event from the 1920s onwards.

Inspection of the raw data indicates the following:

1. Performance in the men's shot put appears to initially evolve slowly, whereas the women's event appears to improve at a greater rate;

2. Performances for both men and women appear to peak during the 1980s before declining and leveling off;

3. The peak in the women's event appears more pronounced than the men's event;

4. There are performance declines emerging during the years of the 1st and 2nd World Wars.

There are many limitations in the modelling of athletic performance data using linear and polynomial models $[1,7,8]$. These types of models become unsuitable for extrapolation beyond an observed range, contain no asymptotes, and some model parameters lack biological meaning. Therefore, it is preferential to use logistic and exponential growth functions when seeking to model the evolution of athletic performance $[5,8,9]$.

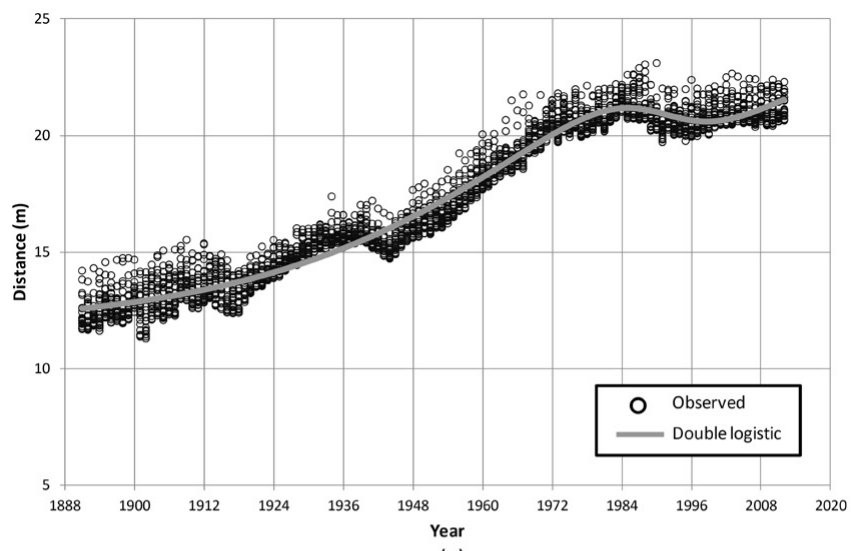

(a)

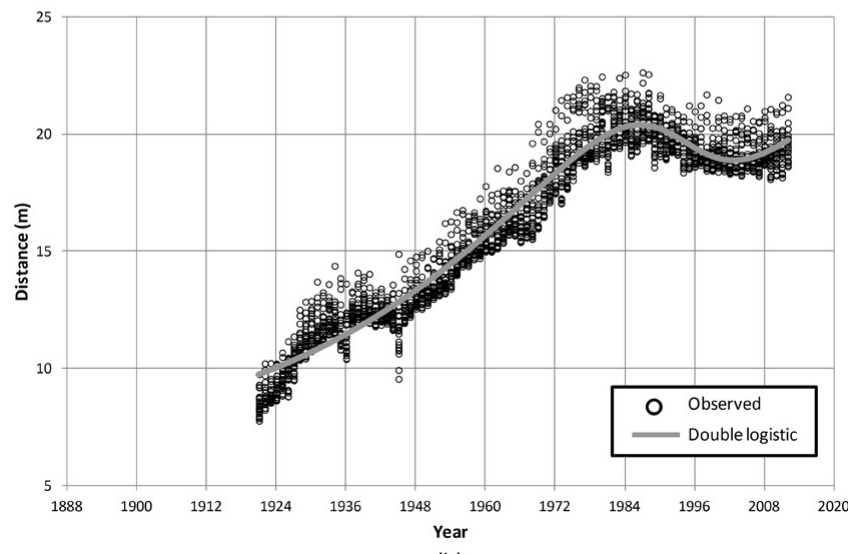

(b)

Figure 1: Double sigmoidal models of the shot put performance over time plotted alongside observed performance values (yearly top 25) for (a) men and (b) women.

In cases where there are two acceleration phases in athletic performance, a double logistic model is preferable because it can detect both the underlying evolutionary global improvement in performances (phase 1), as well as further accelerations in performance as a result of a technological or other interventions (phase 2) [5]. For example, the double logistic model could also be employed to model a second phase performance decline due to implementation of improved drug testing procedures. Equation (1) shows the adapted double logistic model employed by Balmer et al. [5] to search for technological interventions within the jumping category of field events.

$$
\mathrm{f}(\mathrm{t})=\mathrm{P}_{0}+\frac{\mathrm{a}_{1}}{1+\mathrm{e}^{-\mathrm{a}_{2}\left(\mathrm{t}-\mathrm{t}_{1}\right)}}+\frac{\mathrm{b}_{1}}{1+\mathrm{e}^{-\mathrm{b}_{2}\left(\mathrm{t}-\mathrm{t}_{2}\right)}}
$$

The model sums two logistic functions, where $P_{0}$, is the baseline performance at the beginning of the model. $P_{0}+\mathrm{a}_{1}$ is the upper limit of performance which would have been obtained if an intervention had not occurred. $a_{1}$ is the modelled contribution from the underlying evolutional improvement or global improvement of that particular event; $a_{2}$ reflects the rate of this global improvement trend and is symmetrical about $t=t_{1}$, the point of inflection. $b_{1}$ is the contribution to performance of the second phase or the level of effect from the intervention being modelled. $b_{2}$ reflects the rate of change of the second phase and is symmetrical about $t=t_{2}$. Where there is a negative second phase growth (where the product of $b_{1}$ and $b_{2}$ is negative) performance peaks at $P_{0}+a_{1}-\left|b_{1}\right|$ as time tends towards infinity. 
Citation: Foster LI, Haake SJ, James DM, Nevill AM (2014) Modelling Effects of Drug Testing Procedures on Performance Trends in the Shot Put. J Sports Med Doping Stud 4: 151. doi:10.4172/2161-0673.1000151

Page 3 of 5

\begin{tabular}{|c|c|c|c|c|c|c|}
\hline \multirow[b]{2}{*}{ Parameter } & \multicolumn{3}{|c|}{ Men } & \multicolumn{3}{|c|}{ Women } \\
\hline & Estimate & Standard error & $95 \% \mathrm{Cl}$ & Estimate & Standard error & $95 \% \mathrm{Cl}$ \\
\hline $\mathrm{P}_{0}$ & 6.53 & 1.24 & 2.43 & 6.66 & 0.53 & 1.04 \\
\hline$a_{1}$ & 19.77 & 3.18 & 6.23 & 30.46 & 7.76 & 15.21 \\
\hline$a_{2}$ & 0.04 & 0.00 & 0.00 & 0.03 & 0.00 & 0.01 \\
\hline$t_{1}$ & 1980.68 & 7.29 & 14.30 & 1985.55 & 11.74 & 23.01 \\
\hline$b_{1}$ & 5.28 & 1.16 & 2.27 & -8.93 & 2.16 & 4.23 \\
\hline$b_{2}$ & -0.18 & 0.03 & 0.05 & 0.18 & 0.03 & 0.05 \\
\hline$t_{2}$ & 1991.39 & 0.62 & 1.22 & 1994.23 & 0.72 & 1.40 \\
\hline Peak after phase 1 & \multicolumn{3}{|c|}{26.29} & \multicolumn{3}{|c|}{37.12} \\
\hline Peak after phase 2 & \multicolumn{3}{|c|}{21.01} & \multicolumn{3}{|c|}{28.18} \\
\hline $\mathrm{R}^{2}$ & \multicolumn{3}{|c|}{0.9603} & \multicolumn{3}{|c|}{0.9472} \\
\hline $\mathrm{R}^{2}$ adjusted & \multicolumn{3}{|c|}{0.9602} & \multicolumn{3}{|c|}{0.9471} \\
\hline
\end{tabular}

Table 1: Non-linear regression output for the double logistic models of the men's and women's shot put by year.

All performance data available, both for the men's and women's shot put events, were modelled using a double logistic model. The double logistic model was fitted to each data set using non-linear least squares estimation [16] both in SPSS and manually using the solver function in EXCEL to confirm model parameters (see Supplemental Digital Content 1 for the adopted SPSS syntax text).

\section{Results}

(Table 1) shows non-linear regression outputs for the double logistic model when applied to all annual shot put performance data in both the men's and women's events. Fitted and observed data are shown in Figure 1a for the men's event and (Figure 1b) for the women's event. Examining (Table 1), the double logistic model in both the men's and women's shot put have similar baseline values, $6.53 \mathrm{~m}$ and $6.66 \mathrm{~m}$ respectively. The expected growth in the first phase in the men's shot put event is $19.77 \mathrm{~m}$, resulting in an estimated peak of this phase at $26.29 \mathrm{~m}$. This first phase growth is centred around 1981 (Figure 2a). The women's event demonstrated a very large expected growth in the first phase at $30.46 \mathrm{~m}$ resulting in a peak of $37.12 \mathrm{~m}$. The women's first phase growth centred around 1986, slightly later than the male event (Figure 2b). The second phase decline in shot put performance, attributed to the uptake of better drug testing procedures in the men's event, is $5.28 \mathrm{~m}$, with a point of inflection around 1991. In the women's event this modelled decline is $8.93 \mathrm{~m}$, with a point of inflection around 1994 (Figure 2a).

\section{Discussion}

As hypothesised, performance trends in both the men's and women's shot put event showed evidence of two phases: the first phase being positive and the second being negative. All model parameters were significant (i.e., parameter estimates greater than $2^{*} \mathrm{SE}$, see Table 1) and the magnitude of these estimates, together with the explained $R^{2}$ and $\mathrm{R}^{2}$ adjusted, demonstrated that the double sigmoidal model was a good fit to the two data sets.

The estimates associated with the first phase suggested a general evolutionary growth over the whole of the $20^{\text {th }}$ century in both the men and women's shot put performances. The minimum shot put distance value estimates for men and women are very similar at $6.5 \mathrm{~m}$ and 6.7 $\mathrm{m}$ respectively, and the year of maximum acceleration in shot put performance also occurred at approximately 1981 for men and 1986 for women athletes. This maximum acceleration in performance coincides with the prevalence of early systematic steroid doping programs $[11,12]$.

The maximum second phase decline in performance in the women's event is predicted to be $8.93 \mathrm{~m}, 70 \%$ more than the predicted men's second phase decline at $5.28 \mathrm{~m}$. One reason for this large variation is the

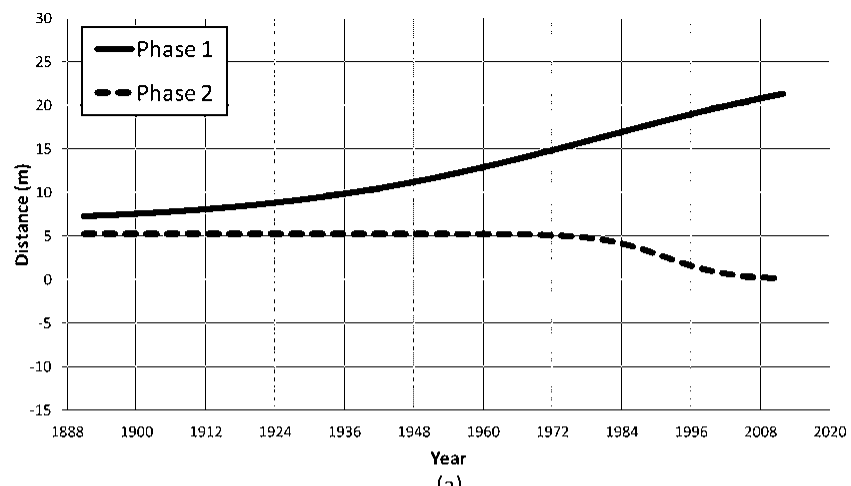

(a)

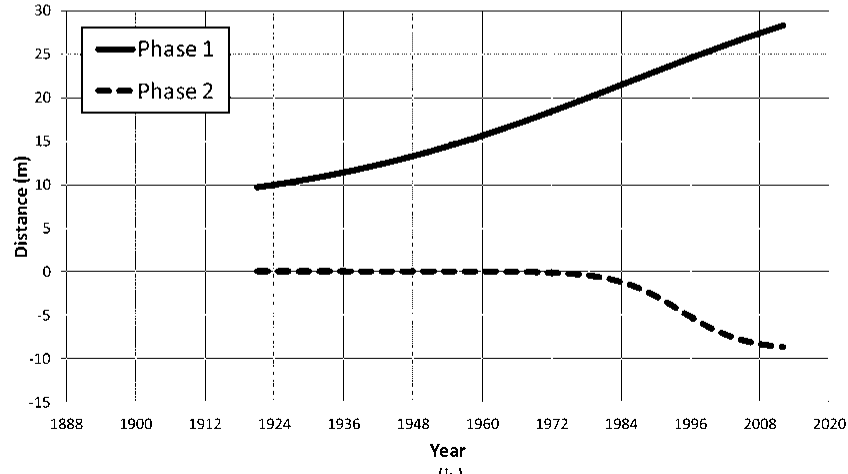

(b)

Figure 2: The first and second phase of growth in the (a) men's and (b) women's shot put, the second phase is attributed to the improvements in drug testing procedures.

difference in mass between the men's and women's shot put. The mass of the women's competition shot $(4 \mathrm{~kg})$ is almost half that of the men's $(7.26 \mathrm{~kg})$. According to Newton's second law of motion, if the athlete can produce an increase in propulsive impulse, the acceleration of a heavier shot will be proportionally smaller, and the increase in distance projected will be smaller. (Table 2) within the supplemental material shows the approximate peak launch velocities and impulse values for men and women shot putters. These values have been calculated by taking the peak throw distances in the ${ }^{\text {st }}$ and $2^{\text {nd }}$ phase growth functions, and applying them to a simple projectile model [17]. The launch angle of the shot was taken to be $38^{\circ}$ and the launch height was assumed to be $2.20 \mathrm{~m}$ for men and $2.07 \mathrm{~m}$ for women, because these parameters are typical values observed in elite shot put performance [16]. It can be seen that the predicted drop in women's performance, due to the onset of 


\begin{tabular}{|l|c|c|c|}
\hline & & Men & Women \\
\hline & Shot mass (kg) & 7.26 & 4 \\
\hline & Launch angle of shot $\left(^{\circ}\right)$ & 37 & 37 \\
\hline \multirow{3}{*}{ Phase 1 growth peak } & Launch height (m) & 2.22 & 2.07 \\
\cline { 2 - 4 } & Throw distance (m) & 26.29 & 37.12 \\
\cline { 2 - 4 } & Launch velocity (ms ${ }^{-1}$ ) & 15.53 & 18.78 \\
\cline { 2 - 4 } Phase 2 growth peak & Impulse (Ns) & 112.77 & 75.12 \\
\hline & Throw distance (m) & 21.01 & 28.183 \\
\cline { 2 - 4 } & Launch velocity (ms $\left.{ }^{-1}\right)$ & 13.71 & 16.19 \\
\cline { 2 - 4 } & Impulse (Ns) & 104.22 & 64.75 \\
\hline & Impulse drop (Ns) & 8.55 & 10.37 \\
\hline & Impulse drop (\%) & $7.58 \%$ & $13.80 \%$ \\
\hline
\end{tabular}

Table 2: Launch velocities and impulse values for the men's and women's doped and un-doped peak performances.

better drug testing protocols, is about $10.37 \mathrm{Ns}$, or $13.80 \%$. This figure is still higher when compared to the men's drop in performance of 8.55 Ns, or $7.58 \%$. This comparison indicated that, based on impulse values, women shot putters were influenced more by the onset of better drug testing protocols. Findings suggest that anti-doping measures have had a greater effect on women's performance than men's. Female physiology with artificially elevated testosterone levels may account for this [18]; the normal levels of testosterone present in females are generally several times lower than males [19]. The artificial administration of this type of hormone could have pushed women's performance close to values for men's performance levels in the absence of doping interventions.

Contemporary female shot putters are predicted to produce about $62 \%$ of the propulsive impulse, compared to male counterparts, whereas a doped women shot putter could have been as close as $72 \%$ to an undoped male counterpart.

Both the modelled second phase reductions in performances appear to be ongoing with both the men's and women's shot put reaching 99.9 $\%$ of the maximum decline in 2030 and 2033 respectively. It is assumed that within $0.1 \%$ of the asymptotic limit, the decline has practically reached this limit. In 2012 the modelled decline in performance in the men's and women's event is at $97.6 \%$ and $96.1 \%$ of the maximum respectively. These data may indicate that anti-doping measures have been successful and that the majority of performance gains seen by doping have almost been eradicated.

(Figure 2) represents the two separate phases of the double logistic model. Phase two begins to have an influence on both events in 1970s with maximum rate (deceleration) of decline in performance in 1991 and 1994 for the men's and women's event respectively. The start of this second phase decline coincides with the first introduction of testing procedures for anabolic steroids at the 1976 Montreal Olympic Games [20]. Eight athletes tested positive for anabolic steroids in those Olympic Games. The peak rate of decline in the men's and women's shot put also occurs slightly after the introduction of out-of-season random drug testing around the late 1980s, the reunification of Germany in 1990, and the fall of the Soviet Union in 1991.

Examining (Figure 2) further, it is apparent that there are two different types of second phase reduction in the men's and women's shot put. The men's event appears to have an underlying positive influence of $5.23 \mathrm{~m}$ from the second phase throughout historic performance data. The positive influence starts to drop to zero with the advent of drug testing in the 1970s. In contrast the women's event experiences zero influence from the second phase function throughout the $20^{\text {th }}$ century and then experiences a negative influence with the onset of drug testing. This statistical evidence suggests that the influence of women's drug taking was a gradual occurrence that was incorporated as part of the evolutionary growth of phase one. In contrast, the men's shot put event may have been influenced by doping measures throughout its more recent history. The development and isolation of steroids like testosterone did not occur until 1930s. However, this does not rule out the historic use of other performance enhancing drugs such as stimulants which may have underlined historic performance, and which are now prohibited and tested as part of anti-doping measures. In the women's event there is no underlying influence from the second phase function, but a negative effect can be seen with the onset of drug testing. One reason for this observation could be that the model finds it difficult to distinguish between the positive effects from doping and the general evolution of the women's shot put event. Therefore, any influence seen from an underlying second phase is hidden within the global evolution from the phase one growth function.

The model parameters show that, if phase two of the double logistic model were omitted, maximum performance in 2012 would reach $26.68 \mathrm{~m}$ in the men's shot put event and $37.12 \mathrm{~m}$ in the women's event. The underlying global progression of athletic performance modelled in the first phase of the double logistic model appears to show that performances are still improving and will not reach $99.9 \%$ of the predict limit until 2167 in the men's and 2183 in the women's shot put event. At first glance, the women's upper limit in shot put performance appears to be unrealistic. Nonetheless, based solely upon Newton's second law of motion, a lighter shot will travel further if propelled at the same force. In theory, and ignoring air resistance, a shot putter who threw a 7.26 $\mathrm{kg}$ shot $26.68 \mathrm{~m}$ will throw a $4 \mathrm{~kg}$ shot $48.42 \mathrm{~m}$. Therefore, a maximum value of $37.12 \mathrm{~m}$ in the women's event does not seem an unreasonable expectation. However, it must be noted that there is a high degree of uncertainty when extrapolating limits from any model that is based solely on historic performance data. This is because it is impossible to account for any future factors and events that may influence performance.

\section{Conclusion}

Up until now, the evidence for any advantage gain of performance enhancing drugs has been mainly anecdotal and subjective. Based on statistical evidence of performance evaluated in this paper it seems apparent that anti-doping measures initially employed in the last two decades of the $20^{\text {th }}$ century have been effective. The result has been a reduction in the men's and women's shot put performances that are likely to now reflect the true limits in shot put performance in the absence of illegal drug assistance.

There will be some uncertainty as to the true effect of performance enhancing drugs on the shot put and other elite sports, as well as uncertainty as to whether their use is still on-going within elite performance programs. However, evidence presented here suggests that performances have declined on top of underlying global performance improvement since the introduction of anti-doping measures in the late 1960s. Therefore, it seems likely that current athletic performances have been influenced to a lesser extent by doping than before drugs testing programs were introduced.

The methods developed in this study reveal that application of a double sigmoidal model to historic performance statistics can be used to objectively detect an intervention, in this case, the effect of antidoping testing measures on shot put performance. These methods could, also be used to gauge other unknown interventions in sports performance statistics, and potentially be a new method used in sports performance analysis. 
Citation: Foster LI, Haake SJ, James DM, Nevill AM (2014) Modelling Effects of Drug Testing Procedures on Performance Trends in the Shot Put. J Sports Med Doping Stud 4: 151. doi:10.4172/2161-0673.1000151

\section{Acknowledgements}

No funding was received for this study.

The authors have no conflict of interest to declare and all authors meet the uniform requirements of the Journal of Sports Medicine \& Doping Studies criteria for authorship.

\section{References}

1. Denny MW (2008) Limits to running speed in dogs, horses and humans. J Exp Biol 2213836-3849.

2. Foster L, James D, Haake SJ (2010) Understanding the influence of population size on athletic performance. Procedia Eng 2: 3183-3189.

3. Lippi G, Banfi G, Favaloro EJ, Rittweger J, Maffulli N (2008) Updates on improvement of human athletic performance: focus on world records in athletics. Br Med Bull 87: 7-15.

4. Haake SJ (2009) The impact of technology on sporting performance in Olympic sports. J Sports Sci 27: 1421-1431.

5. Balmer N, Pleasence P, Nevill A (2012) Evolution and revolution: Gauging the impact of technological and technical innovation on Olympic performance. $J$ Sports Sci 30: 1075-1083.

6. Ernst S, Simon P (2012) A quantitative approach for assessing significant improvements in elite sprint performance: Has IGF-1 entered the arena? Drug Test Anal 5: 384-389.

7. Haake SJ, Foster L, James D (2014) An improvement index to quantify the evolution of performance in running. J Sports Sci 32: 610-622.

8. Foster $L$ (2012) Modelling the effect of technology on elite sport [PhD Thesis]. Sheffield Hallam University 343.
9. Nevill AM, Whyte G (2005) Are there limits to running World Records? Med Sci Sports Exerc 37: 1785-1788.

10. Morton RH (1983) The Supreme Runner: What Evidence Now? Aust J Sports Sci 3: 7-10.

11. Kammerer RC (2001) What Is Doping and How Is It Detected? In: Wilson W, Derse $\mathrm{E}$, editors. Doping in elite sport: the politics of drugs in the Olympic movement. JHK 3-28.

12. Franke WW, Berendonk B (1997) Hormonal doping and androgenization of athletes: a secret program of the German Democratic Republic government. Clin Chem 43: 1262-1279.

13. Berthelot G, Tafflet M, El Helou N, Len S, Escolano S, et al. (2010) Athlete atypicity on the edge of human achievement: performances stagnate after the last peak, in 1988. PLoS One 5: e8800.

14. Rabinovich M (2013) Track and Field Statistics.

15. IAAF (2013) International Association of Athletics Federations, records.

16. Seber GAF, Wild CJ (2003) Nonlinear regression. Hoboken (NJ): WileyInterscience.

17. Linthorne NP (2001) Optimum release angle in the shot put. J Sports Sci 19 359-372.

18. Seiler, S, De Koning, JJ, Foster C (2007) The Fall and Rise of the Gender Difference in Elite Anaerobic Performance 1952-2006. Med Sci Sports Exerc 39: 534-540.

19. Weiss LW, Cureton KJ, Thompson FN (1983) Comparison of serum testosterone and androstenedione responses to weight lifting in men and women. Eur J Appl Physiol 50: 413-419.

20. World anti-doping agency (2013) About WADA website [Internet]. Montreal (Canada): World anti-doping agency. 